\title{
CIRURGIA DE TIKHOFF-LINBERG PARA TRATAMENTO DE CONDROSSARCOMA LOCALMENTE AVANÇADO DA REGIÃO ESCÁPULO-UMERAL
}

\author{
TIKHOFF-LINBERG OPERATION FOR THE TREATMENT OF LOCALLY \\ ADVANCED CHONDROSARCOMA OF THE SCAPULAR GIRDLE REGION
}

\author{
Rony Eshkenazy ${ }^{1}$ \\ Danton Spohr Corrêa, ACBC-SP ${ }^{1}$ \\ Ademar Lopes, TCBC-SP2
}

\section{INTRODUÇÃO}

O condrossarcoma é uma neoplasia maligna originária de células cartilaginosas, mais freqüente em ossos do que em partes moles (proporção 3:1) ${ }^{1}$. É a segunda neoplasia que mais acomete ossos, sendo o osteossarcoma a primeira ${ }^{1}$. A faixa etária em que mais incide é acima dos 20 anos, embora possa ser encontrado em qualquer idade ${ }^{2}$. A sintomatologia apresentada é a dor local associada ao aumento de volume. Originam-se preferencialmente na cintura escapular ou pélvica, não sendo rara sua apresentação em cabeça e pescoço ${ }^{2}$. Os condrossarcomas, principalmente os de baixo grau, habitualmente não respondem a tratamento quimio e radioterápico, e a cirurgia é o tratamento de escolha ${ }^{2}$.

Nosso objetivo é relatar o caso de um paciente com extenso condrossarcoma de região escápuloumeral, previamente com proposta de desarticulação, que foi tratado conservadoramente pela cirurgia de Tikhoff-Linberg, preservando o membro com bons resultados estéticos e funcionais.

\section{RELATO DO CASO}

Paciente do sexo masculino, 45 anos, apresentou-se em nosso serviço com queixa de dor no ombro direito há 1 ano, que vinha sendo tratada com anti-inflamatórios não-hormonais após diagnóstico de tendinite. Referia também aumento do volume do ombro nos últimos meses associada a sensação de formigamento na mão e dificuldade de movimentação do braço direito. Procurou outro serviço médico onde realizou exames de imagem (raio $\mathrm{X}$ simples e ressonância nuclear magnética do ombro direito) e biópsia aberta. $\mathrm{O}$ raio $\mathrm{X}$ do ombro direito demonstrou lesão mista na região metafisária de úmero (medular) com invasão de cortical. A ressonância nuclear magnética apresentou lesão destrutiva da cabeça do úmero direito empurrando partes moles e acometendo a articulação escápulo-umeral (Figura 1). A biópsia aberta da lesão revelou tratar-se de um condrossarcoma de baixo grau. $\mathrm{O}$ exame físico mostrou assimetria entre os ombros, com o direito apresentando abaulamento de partes moles e cicatriz de biópsia de $3,0 \mathrm{~cm}$ em sua face anterior. A palpação mostrou tumoração de consistência dura, pouco dolorosa, fazendo corpo com o plano osteo-articulo-aponevrótico da região escápuloumeral. Os pulsos radial e ulnar estavam preservados e de amplitude normal.

O paciente foi submetido a cirurgia de TikhoffLinberg, sem necessidade de transfusão sangüínea, e recebeu alta no quarto dia de pós-operatório sem intercorrências clínicas. Atualmente encontra-se com 2 anos de seguimento sem evidência de recorrência da doença. O paciente consegue dirigir sem auxilio, pescar

1. Ex-residentes de cirurgia oncológica - Hospital do Câncer AC Camargo, São Paulo, SP.

2. Diretor do Departamento de Cirurgia Pélvica do Hospital do Câncer AC Camargo, São Paulo, SP. Doutor e Livre Docente em Oncologia pela Universidade de São Paulo. 
e carregar objetos tendo vida normal (Figura 2). Este somente não realiza movimentos de abdução, os quais, já não realizava no pré-operatório por motivo de dor.

\section{DISCUSSÃO}

O condrossarcoma é um tumor maligno raro que atinge principalmente pacientes jovens entre $20 \mathrm{e}$ 30 anos de idade ${ }^{1}$. Seu tratamento é eminentemente cirúrgico $^{2}$. A amputação interescápulo-umeral supraumeral ou cirurgia de Tikhoff-Linberg é uma opção cirúrgica conservadora a ser considerada para extensos tumores ósseos e de partes moles da região escápulo-umeral que não podem ser tratados mais conservadoramente $^{3}$. Para que esta operação seja factível, o tumor não pode envolver o feixe vásculonervoso axilar. A clavícula distal, o úmero proximal e parte ou toda a escápula são ressecados. Os níveis

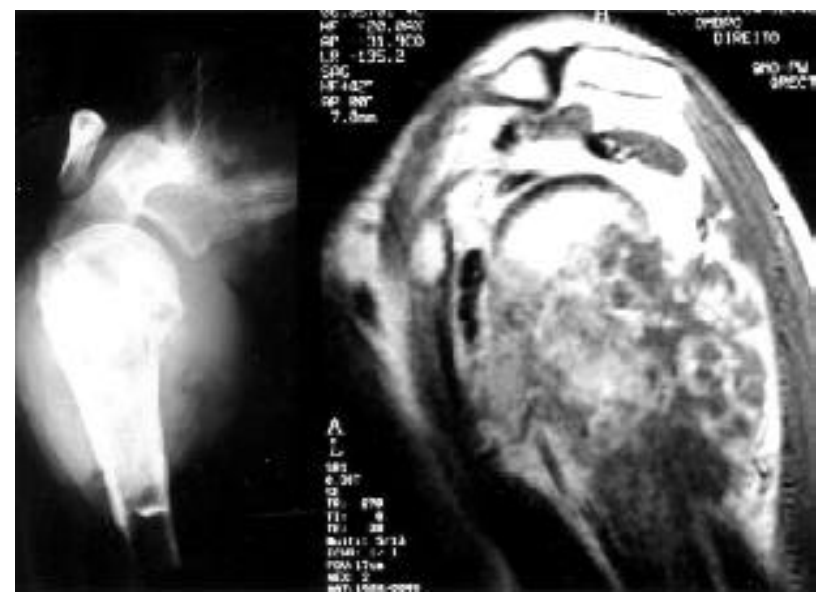

Figura 1 - Imagem ao Raio X da peça operatória e RNM mostrando tumor destruindo a cabeça do úmero. de ressecção podem variar dependendo da extensão do tumor ${ }^{4,5}$.

Neste caso o músculo deltóide foi ressecado em bloco com o tumor, dada a extensão da lesão. Estes pacientes tem $100 \%$ de movimento na articulação do punho e cerca de $50 \%$ de movimentos na articulação do cotovelo ${ }^{4,5}$. A flexão do cotovelo e a estabilidade do ombro podem ser atingidas sem necessidade de órtese (Figura 2). O principal problema pós-operatório é a praxia por tração dos nervos durante a dissecção que normalmente melhora nas primeiras semanas de pós-operatório ${ }^{4,5}$.

A cirurgia de Tikhoff- Linberg é um procedimento cirúrgico que deveria ser mais difundido em nosso meio, já que é uma excelente alternativa à amputação inter-escápulo-torácica para grandes tumores da região escápulo-umeral que não invadem o feixe vásculo-nervoso axilar.

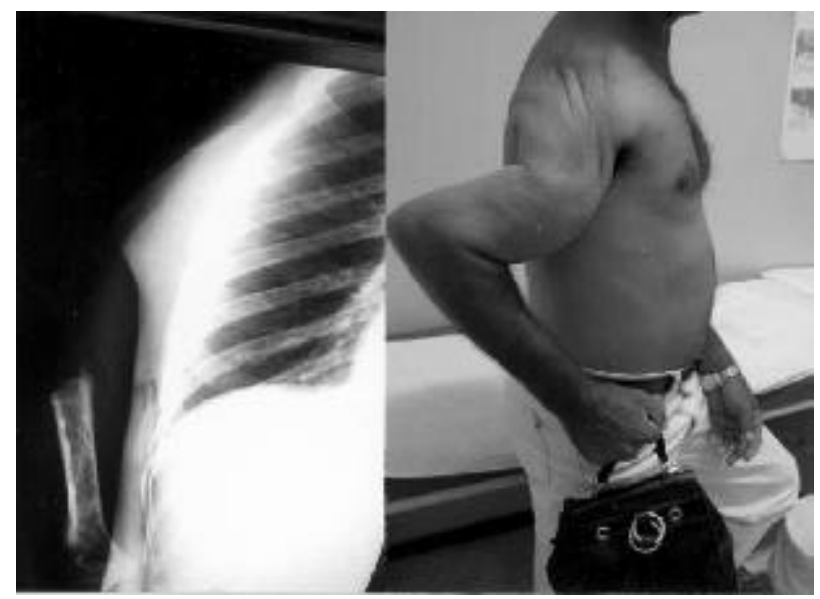

Figura 2 -Raio $X$ do paciente no pós-operatório sem a articulação escápulo-umeral e o mesmo após 6 meses com função do membro preservada.

\begin{abstract}
Chondrosarcoma is a rare malignant neoplasia that most of the time affects young adults. Its location is preferentially the pelvic and scapular girdle and surgery is its treatment of choice. There are no role for chemo or radiation therapy, because of their low index of response. We describe a case of a 45 year-old male patient with an extensive low grade right umerus chondrosarcoma. In spite of the local extension, there was no invasion of the shoulder neurovascular structures. Treatment proposed was the Tikhoff-Linberg procedure, and the operation was performed with success, with no complications. Free margins were obtained. The patient is now on two years follow-up with no evidence of recurrent disease and is able to drive, fish and carry packs. He can not abduct his arm, but he could not do that even before surgery, due to severe pain. We believe this is an excellent conservative approach to such tumors, that otherwise would require a forequarter amputation, and strongly recommend the technique.
\end{abstract}

Key words: Chondrosarcoma; Tumors; Humerus; Surgical procedures, operative. 


\section{REFERENCIAS:}

1. Gitelis S, Bertoni F, Picci P et al. - Chondrosarcoma of bone. The experience at the Istituto Ortopedico Rizzoli. J Bone Joint Surg Am, 1981, 63(8): 1248-1256.

2. Marcove RC. Chondrosarcoma: diagnosis and treatment. Orthop Clin North Am, 1977, 8(4): 811-820.

3. Linberg BE - Interscapulothoracic resection for malignant tumors of the shoulder joint region. J Bone Joint Surg, 1928, 10: 344.

4. Pinto FSC, Lopes A, Epifânio ITN, et al. - Cirurgia conservadora para os tumores da região escápuloumeral: cirurgia de Tikhoff-Linberg. Rev Col Bras Cir, 1986, 13(4): 132-140.
5. Voggenreiter G, Assenmacher S, Schmit-Neuerburg KP - Tikhoff-Linber procedure for bone and soft tissue tumors of the shoulder girdle. Arch Surg, 1999, 134 (3): 252-257.

Endereço para correspondência:

Ademar Lopes

Hospital do Câncer - Departamento de Cirurgia Pélvica

R. Professor Antônio Prudente, 211

Liberdade - São Paulo - SP 01509-900 